\title{
A Dynamic General Equilibrium Model Satisfying Golden Rule in Neoclassical Growth Theory
}

\author{
Jiang Wei ${ }^{{ }^{*}}$, Kangping $\mathrm{Wu}^{1}$, Xuanming $\mathrm{Ni}^{2}$ \\ ${ }^{1}$ School of Economics and Management, Tsinghua University, Beijing, China \\ ${ }^{2}$ School of Software and Microelectronics, Peking University, Beijing, China \\ Email: *weij.09@sem.tsinghua.edu.cn
}

How to cite this paper: Wei, J., Wu, K.P. and Ni, X.M. (2017) A Dynamic General Equilibrium Model Satisfying Golden Rule in Neoclassical Growth Theory. Theoretical Economics Letters, 7, 975-981.

https://doi.org/10.4236/tel.2017.74066

Received: May 21, 2017

Accepted: June 16, 2017

Published: June 19, 2017

Copyright $\odot 2017$ by authors and Scientific Research Publishing Inc. This work is licensed under the Creative Commons Attribution International License (CC BY 4.0).

http://creativecommons.org/licenses/by/4.0/

\begin{abstract}
This paper constructs a model which is more close to the reality to describe individual saving behavior accurately and explain the long-term growth of economy. The model constructed in this paper is the improvement and innovation of neoclassical growth models including Solow model, RCK model and OLG model. Starting from the micro decision making of individuals and firms, there exists balanced growth path (BGP) and capital stock in steady state satisfies the golden rule in general equilibrium. Total saving rate equals the elasticity of output with respect to capital. The long-term economic growth depends on exogenous technological progress.
\end{abstract}

\section{Keywords}

Economic Growth, Dynamic General Equilibrium, Golden Rule

\section{Introduction}

The most representative models in neoclassical growth theory are Solow model, RCK model and OLG model. These models have great influence on economic theory and practice. With the development of macroeconomic theory, researchers pay less and less attention to neoclassical growth theory. This paper tries to integrate the advantages of the three famous models to establish a unified neoclassical growth model.

Solow model takes technological progress as given and investigates the effects of the division of output between consumption and investment on capital accumulation and growth. The shortage of Solow model is the lack of micro foundation and saving rate is exogenous given. Golden rule cannot guarantee the maximum utility of individuals [1]. 
RCK model relaxes the Solow model's assumption that the saving rate is exogenous and fixed. RCK model is setup in dynamic general equilibrium (DGE) framework and thus has micro foundation. Saving rate is endogenously derived in this model. One shortage is that capital stock in steady state is less than golden rule level and capital stock satisfying golden rule is unstable in this model. The other is that assumption of living forever does not conform to the reality and there are no old people also called retired people in this model [2] [3] [4].

OLG model has heterogeneous consumers in which the young and old overlap at each period and thus it is more close to reality. The weakness of OLG model is the possibility of dynamic inefficiencies. Capital stock in steady state may exceed golden rule level and thus there exits Pareto improvement. Another shortage is the simplification of lifetime to two discrete time points. Although analysis procedure is simplified, we cannot accurately describe the consumption path of individuals [5] [6].

We integrate the advantages of Solow model, RCK model and OLG model to construct a new growth model. In the model, time is continuous and there are newborn people at any time. Individuals live in working period and retirement period. Starting from the micro decision making of individuals and firms, there exists balanced growth path and capital stock in steady state satisfies the golden rule in general equilibrium.

The paper is organized as follows. Section 2 presents the model. Section 3 analyzes the model. Section 4 gives a brief conclusion.

\section{Model}

\subsection{Firms}

There exist large numbers of firms in the economy. Firms rent capital and labor in factor markets. Individuals purchase goods in competitive markets. The production takes the form

$$
Y(t)=F(K(t), A(t) L(t))
$$

where technological progress is exogenous, $\frac{\dot{A}(t)}{A(t)}=g, A(t)=A(0) \cdot \mathrm{e}^{g t}$.

Define $k=\frac{K}{A L}, y=\frac{Y}{A L}=\frac{F(K, A L)}{A L}, k$ is the amount of capital per unit of effective labor and $y$ is output per unit of effective labor. Then we rewrite production function as

$$
y=f(k)
$$

The intensive-form production function, $f(k)$, is assumed to satisfy $f(0)=0, f^{\prime}(k)>0, \quad f^{\prime \prime}(k)<0, \lim _{k \rightarrow 0} f^{\prime}(k)=\infty, \lim _{k \rightarrow \infty} f^{\prime}(k)=0$.

In competitive market, profit maximization will yield that interest rate equals marginal product of capital

$$
r(t)=f^{\prime}(k(t))
$$


wage equals marginal product of labor

$$
\omega(t)=f(k(t))-k(t) f^{\prime}(k(t))
$$

\subsection{Individuals}

Referring to Futagami and Nakajima [7], we suppose that a person is born at time $x$, work to $x+d$ and die at time $x+m$. A person works between age 0 and $d$ to earn money and purchases goods between age 0 and $m$.

Furthermore, we give some additional demographic assumptions. Each individual has fixed lifespan $m$ and that is to say, at any given time $t$, there exist individuals from age 0 to $m$. For the overall population to be growing at rate $n$ and the age distribution to be well behaved, the number of people born per unit time is growing at rate $n$.

Define $B(t)$ as newborn population at time $t$,

$$
\frac{\dot{B}(t)}{B(t)}=n, \quad B(t)=B(0) \cdot \mathrm{e}^{n t}
$$

where $n$ is newborn growth rate.

Total population at time $t$ is described as

$$
\begin{gathered}
N(t)=\int_{t-m}^{t} B(0) \cdot \mathrm{e}^{n x} \mathrm{~d} x=\frac{B(0)}{n}\left(\mathrm{e}^{n t}-\mathrm{e}^{n(t-m)}\right) \\
\frac{\dot{N}(t)}{N(t)}=\frac{\frac{B(0)}{n}\left(n \cdot \mathrm{e}^{n t}-n \cdot \mathrm{e}^{n(t-m)}\right)}{\frac{B(0)}{n}\left(\mathrm{e}^{n t}-\mathrm{e}^{n(t-m)}\right)}=n
\end{gathered}
$$

Total labor in economy is

$$
\begin{gathered}
L(t)=\int_{t-d}^{t} B(0) \cdot \mathrm{e}^{n x} \mathrm{~d} x=\frac{B(0)}{n}\left(\mathrm{e}^{n t}-\mathrm{e}^{n(t-d)}\right) \\
\frac{\dot{L}(t)}{L(t)}=\frac{\frac{B(0)}{n}\left(n \cdot \mathrm{e}^{n t}-n \cdot \mathrm{e}^{n(t-d)}\right)}{\frac{B(0)}{n}\left(\mathrm{e}^{n t}-\mathrm{e}^{n(t-d)}\right)}=n
\end{gathered}
$$

Total old people or retired people in economy are

$$
\begin{gathered}
O(t)=\int_{t-m}^{t-d} B(0) \cdot \mathrm{e}^{n x} \mathrm{~d} x=\frac{B(0)}{n}\left(\mathrm{e}^{n(t-d)}-\mathrm{e}^{n(t-m)}\right) \\
\frac{\dot{O}(t)}{O(t)}=\frac{\frac{B(0)}{n}\left(n \cdot \mathrm{e}^{n(t-d)}-n \cdot \mathrm{e}^{n(t-m)}\right)}{\frac{B(0)}{n}\left(\mathrm{e}^{n(t-d)}-\mathrm{e}^{n(t-m)}\right)}=n
\end{gathered}
$$

We have

$$
\frac{\dot{N}(t)}{N(t)}=\frac{\dot{L}(t)}{L(t)}=\frac{\dot{O}(t)}{O(t)}=n
$$




$$
l(t)=1-o(t)=\frac{L(t)}{N(t)}=\frac{\frac{B(0)}{n}\left(\mathrm{e}^{n t}-\mathrm{e}^{n(t-d)}\right)}{\frac{B(0)}{n}\left(\mathrm{e}^{n t}-\mathrm{e}^{n(t-m)}\right)}=\frac{1-\mathrm{e}^{-n d}}{1-\mathrm{e}^{-n m}}
$$

where $l(t)$ denotes proportion of the workforce, $o(t)$ denotes elderly population proportion.

In the economy, each person has constant relative risk averse (CRRA) utility function as follows

$$
u(C(x, t))=\frac{C(x, t)^{(1-\theta)}}{1-\theta}, \theta>0
$$

where $C(x, t)$ denotes one's consumption and $\theta$ denotes the constant coefficient of relative risk aversion.

Asset per effective labor is accumulated as

$$
\begin{gathered}
\dot{a}(x, t)=\omega(t)+(r(t)-g) a(x, t)-c(x, t) \\
\omega(x, t)=\left\{\begin{array}{l}
\omega(t), x \leq t \leq x+d \\
0, x+d<t \leq x+m
\end{array}\right. \\
a(x, x)=a(x, x+m)=0
\end{gathered}
$$

Each person maximizes his whole life utility

$$
\begin{gathered}
\max \int_{x}^{x+m} \mathrm{e}^{-\rho(t-x)} \frac{C(x, t)^{(1-\theta)}}{1-\theta} \mathrm{d} t \\
\Leftrightarrow \max A(0)^{(1-\theta)} \mathrm{e}^{\rho x} \int_{x}^{x+m} \mathrm{e}^{-(\rho-g(1-\theta)) t} \frac{c(x, t)^{(1-\theta)}}{1-\theta} \mathrm{d} t \\
\Leftrightarrow \max \int_{x}^{x+m} \mathrm{e}^{-(\rho-g(1-\theta)) t} \frac{c(x, t)^{(1-\theta)}}{1-\theta} \mathrm{d} t
\end{gathered}
$$

Combine (14)(15)(16)(19) and use optimal control method, we can derive

$$
\begin{gathered}
\frac{\dot{c}(x, t)}{c(x, t)}=\frac{r(t)-\rho-\theta g}{\theta} \\
c(x, x)=\frac{\int_{x}^{x+d} \omega(v) \mathrm{e}^{-R(x, v)} \mathrm{d} v}{\int_{x}^{x+m} \mathrm{e}^{P(x, v)-R(x, v)} \mathrm{d} v} \\
c(x, t)=\frac{\int_{x}^{x+d} \omega(v) \mathrm{e}^{-R(x, v)} \mathrm{d} v}{\int_{x}^{x+m} \mathrm{e}^{P(x, v)-R(x, v)} \mathrm{d} v} \cdot \mathrm{e}^{P(x, t)}
\end{gathered}
$$

where $P(x, v)=\int_{x}^{v} \frac{r(t)-\rho-\theta g}{\theta} \mathrm{d} t, R(x, v)=\int_{x}^{v}(r(t)-g) \mathrm{d} t$.

\subsection{Equilibrium}

At any given time $t$, there exist individuals from age 0 to $m$. Aggregate consumption at time $t$ is given by

$$
c_{N}(t)=\int_{t-m}^{t} B(x) c(x, t) \mathrm{d} x=\int_{t-m}^{t} B(0) \mathrm{e}^{n x} c(x, t) \mathrm{d} x
$$


Capital per effective labor is accumulated as

$$
\dot{k}(t)=f(k)-\frac{c_{N}(t)}{L(t)}-k(t)(g+n)
$$

We have $\dot{k}=0$ when economy is in equilibrium. Interest rate and wage are both constant. We can yield that

$$
f(k) \frac{\omega\left(\frac{r}{\theta}-\frac{\rho}{\theta}-r\right)\left(\mathrm{e}^{(g-r) d}-1\right)\left(\mathrm{e}^{\left(\frac{r-\rho-\theta g}{\theta}-n\right) m}-1\right) n}{\left(\mathrm{e}^{\left(\frac{r}{\theta}-\frac{\rho}{\theta}-r\right) m}-1\right)(g-r)\left(\frac{r-\rho-\theta g}{\theta}-n\right)\left(1-\mathrm{e}^{-n d}\right)}=k(g+n)
$$

where $r=f^{\prime}(k), \omega=f(k)-k f^{\prime}(k)$. Parameters $\{\rho, \theta, d, m, n, g\}$ are exogenous.

\section{BGP and Steady State}

Using numerical simulation method (assume Cobb-Douglas function of production), we can solve Equation (25) and yield $k_{1}, k_{2}$. From Figure $1, k_{1}$ is unstable and $k_{2}$ is stable. So capital per effective labor on balanced growth path is $k_{2}$.

Furthermore, we can derive that

$$
f^{\prime}\left(k^{*}\right)=f^{\prime}\left(k_{2}\right)=g+n
$$

This is the important finding of this paper. Capital stock in steady state is only related to $(g+n)$ and production function, but has nothing to do with $\{\rho, \theta, d, m\}$. More importantly, capital stock satisfies the golden rule and the economy can achieve the highest efficiency.

Total saving rate is given by

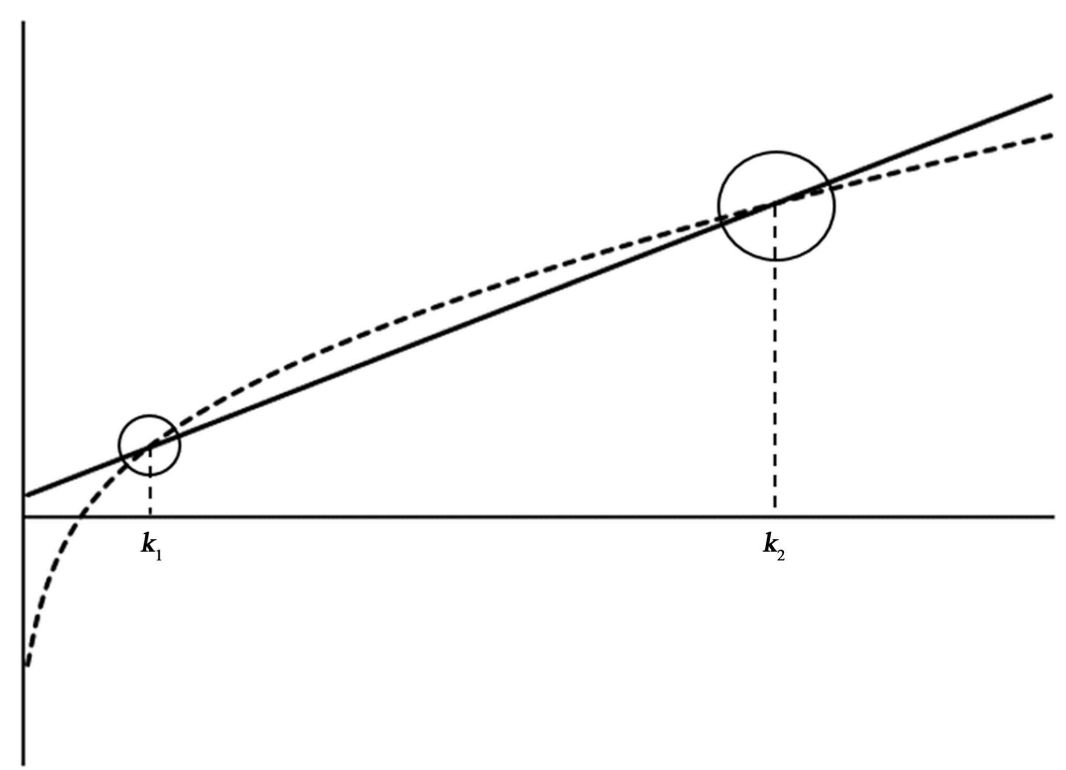

Figure 1. Equilibrium solution to capital per effective labor. Note: short dash line denotes left of Equation (25) and solid line denotes right of Equation (25). 


$$
\begin{aligned}
s & =1-\frac{A(t) c_{N}(t)}{A(t) L(t) f(k)}=1-\frac{c_{N}(t)}{L(t) f(k)} \\
& =1-\frac{\omega\left(\frac{r}{\theta}-\frac{\rho}{\theta}-r\right)\left(\mathrm{e}^{(g-r) d}-1\right)\left(\mathrm{e}^{\left(\frac{r-\rho-\theta g}{\theta}-n\right) m}-1\right) n}{f(k)\left(\mathrm{e}^{\left(\frac{r}{\theta}-\frac{\rho}{\theta}-r\right) m}-1\right)(g-r)\left(\frac{r-\rho-\theta g}{\theta}-n\right)\left(1-\mathrm{e}^{-n d}\right)}
\end{aligned}
$$

With $r=g+n$, we get

$$
s=\frac{k f^{\prime}(k)}{f(k)}
$$

So total saving rate equals the elasticity of output with respect to capital.

On balanced growth path, capital per effective labor keeps unchanged. We have

$$
\frac{\dot{Y}}{Y}=\frac{\dot{K}}{K}=\frac{\dot{A}}{A}+\frac{\dot{L}}{L}+\frac{\dot{k}}{k}=g+n
$$

From this, long-term economic growth depends on the newborn growth rate and the rate of technological progress.

Capital per capita and output per capita are given by

$$
\frac{K}{N}=\frac{A L k}{N}=A k \cdot \frac{1-\mathrm{e}^{-n d}}{1-\mathrm{e}^{-n m}}, \frac{Y}{N}=\frac{A L f(k)}{N}=A f(k) \cdot \frac{1-\mathrm{e}^{-n d}}{1-\mathrm{e}^{-n m}}
$$

In the long term, output per capita depends only on technological progress.

\section{Conclusions}

This paper establishes a unified neoclassical growth model which can integrate the advantages of the three representative neoclassical growth models including Solow model, RCK model and OLG model to describe individual saving behavior accurately and explain the long-term growth of economy. Starting from the micro decision making of individuals and firms, there exists balanced growth path and capital stock in steady state satisfies the golden rule in general equilibrium. Total saving rate equals the elasticity of output with respect to capital.

For further study, we will introduce government into the model and examine the impact of taxation policy. Another direction of exploration is to make technological progress endogenously.

\section{Acknowledgements}

We would like to thank Koichi Futagami and Tetsuya Nakajima for their paper published in 2001 which triggered our thinking. We also thank Chao Yang and Xiao Chen in Tsinghua University who give helpful comments and suggestions.

\section{References}

[1] Solow, R.M. (1956) A Contribution to the Theory of Economic Growth. Quarterly Journal of Economics, 70, 65-94. https://doi.org/10.2307/1884513

[2] Ramsey, F.P. (1928) A Mathematical Theory of Saving. Economic Journal, 38, $543-$ 
559. https://doi.org/10.2307/2224098

[3] Cass, D. (1965) Optimum Growth in an Aggregative Model of Capital Accumulation. Review of Economic Studies, 32, 233-240. https://doi.org/10.2307/2295827

[4] Koopmans, T.C. (1965) On the Concept of Optimal Economic Growth. In The Econometric Approach to Development Planning, Amsterdam North Holland.

[5] Samuelson, P.A. (1958) An Exact Consumption-Loan Model of Interest with or without the Social Contrivance of Money. Journal of Political Economy, 66, 467482. https://doi.org/10.1086/258100

[6] Diamond, P.A. (1965) National Debt in a Neoclassical Growth Model. American Economic Review, 55, 1126-1150.

[7] Futagami, K. and Nakajima, T. (2001) Population Aging and Economic Growth. Journal of Macroeconomics, 23, 31-44.

Submit or recommend next manuscript to SCIRP and we will provide best service for you:

Accepting pre-submission inquiries through Email, Facebook, LinkedIn, Twitter, etc. A wide selection of journals (inclusive of 9 subjects, more than 200 journals)

Providing 24-hour high-quality service

User-friendly online submission system

Fair and swift peer-review system

Efficient typesetting and proofreading procedure

Display of the result of downloads and visits, as well as the number of cited articles Maximum dissemination of your research work

Submit your manuscript at: http://papersubmission.scirp.org/

Or contact tel@scirp.org 